\title{
Students' Self-Perceptions of Self-Awareness/Self-Regulation when Experiencing Unexpected Situations in an Interprofessional Clinical Simulation
}

\author{
Elena Wong Espiritu \\ Belmont University, Elena.espiritu@belmont.edu \\ Steven Busby PHD, FNP-BC \\ Belmont University, steven.busby@belmont.edu \\ Julie W. Hunt \\ Belmont University, julie.hunt@belmont.edu \\ Renee Brown \\ Belmont University, renee.brown@belmont.edu \\ Beth F. Hallmark \\ Belmont University, beth.hallmark@belmont.edu \\ Follow this and additional works at: https://nsuworks.nova.edu/ijahsp \\ Part of the Medicine and Health Sciences Commons
}

This Manuscript has supplementary content. View the full record on NSUWorks here: https://nsuworks.nova.edu/ijahsp/vol19/iss1/11

\section{Recommended Citation}

Espiritu EW, Busby S, Hunt JW, Brown R, Hallmark BF, Cochran K, et al. Students' Self-Perceptions of SelfAwareness/Self-Regulation when Experiencing Unexpected Situations in an Interprofessional Clinical Simulation. The Internet Journal of Allied Health Sciences and Practice. 2021 Jan 01;19(1), Article 11.

This Manuscript is brought to you for free and open access by the College of Health Care Sciences at NSUWorks. It has been accepted for inclusion in Internet Journal of Allied Health Sciences and Practice by an authorized editor of NSUWorks. For more information, please contact nsuworks@nova.edu. 


\title{
Students' Self-Perceptions of Self-Awareness/Self-Regulation when Experiencing Unexpected Situations in an Interprofessional Clinical Simulation
}

\begin{abstract}
Background: The healthcare environment is becoming increasingly complex and demanding; therefore, providers need to possess both technical and non-technical skills to respond in unexpected circumstances. Self-awareness and regulation are non-technical skills where an individual becomes aware of personal and others' emotions and then modulates those emotions to effectively act during a challenging situation. Educational programs need to embed more opportunities for students to develop these skills to enhance patient outcomes. Purpose: The purpose of this research study was to explore student self-perceptions of self-awareness and self-regulation when experiencing unexpected situations in an interprofessional clinical simulation. Methods: Healthcare students $(n=109)$ from four disciplines participated in this qualitative research study involving an interprofessional small group, face to face simulation with unexpected circumstances. Following the simulation, participants engaged in a semistructured debriefing. Comments were recorded and analyzed to develop a thematic structure. Results: Participants had varying views about their level of preparedness to handle complex, unexpected situations ranging from feeling not prepared at all to recognizing that they need to be equipped for anything. Students also reported a greater appreciation for the interprofessional team, acknowledging the need for one another as they navigated unexpected circumstances. Some students used their self-awareness and regulation skills in the moment to manage their emotions and move to action in response to the unexpected circumstances, while others benefited from observing and hearing from others during the simulation and debriefing session. Conclusions: The interprofessional simulation helped to prepare students to navigate unexpected challenging patient care circumstances. Students experienced some role and action confusion in response to the emotionally charged scenario; however, they recognized the importance of being self-aware, regulating their own emotions and the skills of the interdisciplinary team to best meet the needs of the patient and family. Additional opportunities for non-technical skill practice should be included in healthcare curriculums to enhance students' preparedness for the current healthcare environment. Further research is recommended to determine best practices for teaching these non-technical skills.
\end{abstract}

\section{Author Bio(s)}

Elena Wong Espiritu, OTD, OTR/L, BCPR is an Associate Professor in the School of Occupational Therapy at Belmont University. Prior to academia, she worked 10 years in the adult physical disabilities setting providing acute care, inpatient acute rehabilitation and outpatient services as a clinician and team coordinator.

Steven Busby, PhD, FNP-BC has delivered healthcare for 35 years. He worked as an EMT/Paramedic, as an RN in CVICU, ER and as a hospital nursing educator teaching critical care. He has been a family nurse practitioner for 22 years and has 16 years of higher education teaching experience.

Julie Hunt, MSSW, LCSW is an Associate Professor of Social Work \& Director of Field Education at Belmont University. She teaches in the areas of practice and field. Her scholarship is focused on teaching and learning as it pertains to clinical practice, spirituality, human diversity, and empathy.

Renee Brown, PT, PhD is the Associate Dean for College of Health Sciences and Nursing at Belmont University and Professor in the School of Physical Therapy.

Beth Hallmark, PhD, RN, MSN, CHSE is the Director of Simulation for the College of Health Sciences and Nursing at Belmont University and is a faculty member in the School of Nursing. 
Keri Cochran, MSN-Ed, RNC-NIC is a Simulation Specialist in the College of Health Sciences and Nursing at Belmont University. In her role, she works with course faculty to develop, coordinate, facilitate, and evaluate healthcare simulations. Prior to Belmont, she worked for more than 20 years as a critical care nurse.

Carol Krueger-Brophy, PT, JD has enjoyed careers in both physical therapy and health law. At the time this study was conducted, she was an adjunct faculty member in the School of Physical Therapy at Belmont University teaching healthcare ethics.

\section{Authors}

Elena Wong Espiritu; Steven Busby PHD, FNP-BC; Julie W. Hunt; Renee Brown; Beth F. Hallmark; Keri Cochran; and Carol Krueger-Brophy 


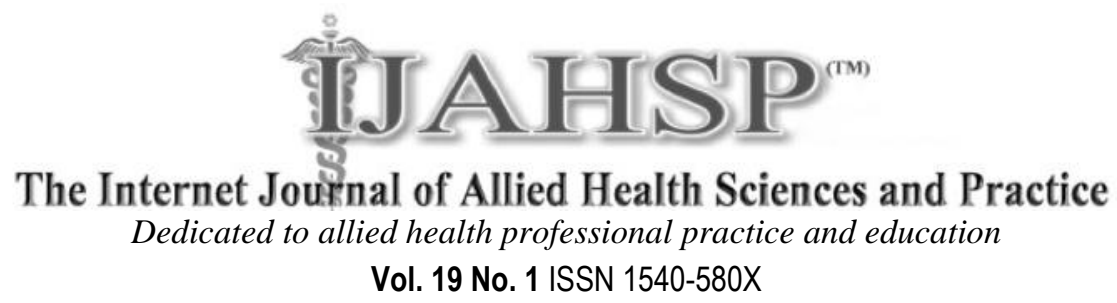

Vol. 19 No. 1 ISSN 1540-580X

\title{
Students' Self-Perceptions of Self-Awareness/Self-Regulation when Experiencing Unexpected Situations in an Interprofessional Clinical Simulation
}

\author{
Elena Wong Espiritu \\ Steven Busby \\ Julie W. Hunt \\ Renee Brown \\ Beth F. Hallmark \\ Keri Cochran \\ Carol Kureger-Brophy \\ Belmont University \\ United States
}

\begin{abstract}
Background: The healthcare environment is becoming increasingly complex and demanding; therefore, providers need to possess both technical and non-technical skills to respond in unexpected circumstances. Self-awareness and regulation are non-technical skills where an individual becomes aware of personal and others' emotions and then modulates those emotions to effectively act during a challenging situation. Educational programs need to embed more opportunities for students to develop these skills to enhance patient outcomes. Purpose: The purpose of this research study was to explore student self-perceptions of self-awareness and self-regulation when experiencing unexpected situations in an interprofessional clinical simulation. Methods: Healthcare students $(n=109)$ from four disciplines participated in this qualitative research study involving an interprofessional, small group, face to face simulation with unexpected circumstances. Following the simulation, participants engaged in a semi-structured debriefing. Comments were recorded and analyzed to develop a thematic structure. Results: Participants had varying views about their level of preparedness to handle complex, unexpected situations ranging from feeling not prepared at all to recognizing that they need to be equipped for anything. Students also reported a greater appreciation for the interprofessional team, acknowledging the need for one another as they navigated unexpected circumstances. Some students used their self-awareness and regulation skills in the moment to manage their emotions and move to action in response to the unexpected circumstances, while others benefited from observing and hearing from others during the simulation and debriefing session. Conclusions: The interprofessional simulation helped to prepare students to navigate unexpected challenging patient care circumstances. Students experienced some role and action confusion in response to the emotionally charged scenario; however, they recognized the importance of being self-aware, regulating their own emotions and the skills of the interdisciplinary team to best meet the needs of the patient and family. Additional opportunities for non-technical skill practice should be included in healthcare curriculums to enhance students' preparedness for the current healthcare environment. Further research is recommended to determine best practices for teaching these non-technical skills.
\end{abstract}

Keywords: interprofessional, self-awareness, self-regulation, simulation, unexpected 


\section{INTRODUCTION AND BACKGROUND}

To be successful within an ever-changing, increasingly complex healthcare environment, healthcare professionals need to possess skills beyond the typical technical, discipline-specific abilities, which are learned in their training. ${ }^{1-3}$ Non-technical skills are "the cognitive, social and personal resource skills that complement technical skills and contribute to safe and efficient task performance."4 Non-technical skills, such as the ability to make decisions, provide compassionate care through genuine interpersonal interactions, effectively communicate with others, and possessing self-awareness and self-regulation through emotional intelligence, are important for leadership development and promoting teamwork. ${ }^{1-2,4-9}$ True interdisciplinary teamwork is achieved when practitioners entrusted to deliver healthcare services can blend technical competence with service orientation. ${ }^{10}$

The need for healthcare providers to be emotionally intelligent and maintain overall mental health for effective practice, is well supported in the literature.3,6,11 Emotional intelligence involves a person's ability to recognize one's own emotions and others' emotions to guide thoughts and actions to cope with pressures and stresses that occur within an environment. ${ }^{12-14}$ People that demonstrate self-awareness recognize their personal moods, emotions, and feelings and how these emotions affect themselves, others, and their job performance. ${ }^{15}$ Professionals who are self-aware exhibit self- confidence and rely on their strengths. They have a realistic understanding of their emotions and capabilities by being honest with themselves and others and are willing to ask for help when needed. ${ }^{15}$ Conversely, those who do not demonstrate self-awareness have the tendency to make decisions that are inconsistent with their personal values and set themselves up for failure by taking on challenges that they cannot handle on their own. ${ }^{15}$ After identifying unhelpful moods and emotions through self-awareness, self-regulation is the component of emotional intelligence that allows a person to modulate the intensity and duration of emotional states by controlling impulses, thinking before acting and redirecting feelings into more constructive avenues. ${ }^{15-16}$ Self-regulation aids a person in being reasonable, open to change, reflective, and able to remain calm in response to unanticipated events. ${ }^{15}$

Self-awareness and self-regulation are two elements of emotional intelligence that are particularly vital for healthcare providers to possess as medical environments can be stressful and demanding. Unexpected and uncertain circumstances frequently occur in settings with dynamic patient and family situations. Therefore, healthcare providers must maintain emotional and cognitive control when caring for a patient in the face of an unpredicted event by being aware of their own feelings and stress and respond in a focused and appropriate manner. ${ }^{17}$ Professionals should not panic but instead be able to identify information and behaviors for effective interdisciplinary teamwork and maintain patient safety. ${ }^{17-18}$ Healthcare practitioners also need to demonstrate emotional intelligence throughout their professional lifetime to combat burnout, maintain optimal patient care, achieve job satisfaction, and continue career development. ${ }^{19-24}$

For healthcare professionals to demonstrate emotional control during challenging situations, skill development must begin with educational programs providing opportunities for students to practice these attributes and skills throughout their curriculums.3,6,11 Students need to practice within safe and supportive environments and without the pressures of endangering patients rather than relying on "on the job training" during clinical placements. ${ }^{4,25}$ However, there is little information available for faculty regarding the structure and evaluation of such learning experiences. 6,8

Simulation education is an experiential learning opportunity that bridges the gap between the classroom and practice by providing students with a clinical context where they can practice skills and patient interaction without the added risk and pressure of real patients. ${ }^{18,26-27}$ Simulations have been shown to aid in the development of student competencies in the areas of communication, teamwork, clinical-decision making, and intervention practice. ${ }^{27-31}$ Standardized actors, who are people well trained to play a patient or caregiver role, can add to the "real life" feeling during the simulation and provide valuable opportunities for students to practice their non-technical skills through well-crafted interactions and feedback. ${ }^{27,32-33} \mathrm{An}$ essential component of the simulation process is debriefing after the simulated experience. This provides students with the opportunity to reflect on their actions and responses during patient and interdisciplinary team interactions, which can lead to increased self-awareness and self-efficacy related to strengths and areas for improvement. ${ }^{18,34-36}$ Simulation using standardized actors can especially be helpful in training students to handle unforeseen and challenging situations, compared to solely using mannequins. ${ }^{18,37}$

While it is important for an individual healthcare provider to possess these non-technical skills of self-awareness and self-regulation, healthcare does not take place in isolation. Therefore, healthcare professionals need to be able to demonstrate these skills within an interdisciplinary team environment. 10,18 Recognizing the importance of interdisciplinary teamwork on improving overall patient outcomes, there has been an increasing emphasis on providing interprofessional educational opportunities for students to develop a team-oriented mindset and skills during their training. The Interprofessional Education Collaborative (IPEC) released a list of core competencies focused on teamwork, communication, values and ethics, and roles and responsibilities, which has helped educators develop interprofessional education opportunities for their students..$^{38}$ 
The literature fully supports the need for healthcare professionals to possess technical and non-technical skills because the healthcare system is complex, demanding skilled patient care and interdisciplinary team collaboration. There is also evidence supporting the effectiveness of disciple-specific and interdisciplinary simulations using standardized actors to provide students with the opportunity to practice clinical skills and patient interactions in a non-threatening and safe environment. However, there is a lack of literature that specifically addresses using interprofessional clinical simulations to develop self-awareness and selfregulation skills in healthcare students during unanticipated situations. The purpose of this research study was to explore student self-perceptions of self-awareness and self-regulation when experiencing unexpected situations in an interprofessional clinical simulation.

\section{METHODOLOGY}

This research was an exploratory qualitative study of student self-perceptions of self-awareness and self-regulation when experiencing unexpected situations in an interprofessional clinical simulation. Approval was granted from Belmont University's Institutional Review Board (IRB).

\section{Research Design}

Healthcare students participated in an interprofessional simulation and subsequent debriefing sessions. Debriefings were conducted as focus groups from which primary data were collected. A qualitative descriptive approach was taken for data analysis and thematic structure development.

Each student participated in the simulation one time within a small group of four students; however, in order to accommodate all students, there were multiple rounds of simulation with each round consisting of nine simulations being conducted simultaneously across three simulation labs. At the conclusion of the simulation round, the students from each simulation lab participated in a 30 minute debriefing session facilitated by trained faculty members. Approximately 24 students participated in each of the four debriefing sessions.

A total of six faculty members, representing all disciplines, were involved in the simulation planning, execution, and debriefing process. The faculty members received one hour of debriefing training, which consisted of a combination of didactic teaching and facilitation practice. There was also one simulation staff member assigned to each lab to coordinate the technical aspects of the simulation. The standardized actors received the simulation script in advance; however, on the day of the event, they were provided with a briefing to ensure that all actors understood the purpose of the simulation and the intent of the interpersonal interactions between the patient's family member, spouse, and students. Many of the actors used in this study had been involved in this simulation for multiple years so they were well-versed in the nuances of the simulation. Costs associated with the simulation including standardized actors' rates and refreshments were covered through the College of Health Sciences' interprofessional education funds.

\section{Recruitment}

Students from nursing, occupational therapy (OT), physical therapy (PT) and social work (SW) participated in an end of life simulation. The entry-level OT and PT doctoral students completed the simulation as part of a course requirement, while the nursing and SW undergraduate students, in their junior and senior years, volunteered to participate. The SW students were enrolled in a junior level practice class and invited by their instructor to take part in the simulation. In exchange for their participation in the simulation, the students earned extra credit on their final exam. The nursing students were invited to participate in the simulation via an email from their instructor.

Prior to participating in the simulation, all students were informed of the research project and invited to participate in the study, which would involve having their comments during the debriefing session recorded, and willing students signed informed consent paperwork. Those that chose not to participate in the study still participated in the debriefing, but their comments were not recorded or used in the study.

\section{Data Collection}

\section{Methods and Instrumentation}

Student comments were collected via a recording device. When speaking, students were instructed not to identify themselves or others by using names or disciplines. The recordings were transcribed by a professional independent transcription service to ensure accuracy, eliminate any possibility of voice recognition with any specific comments, and preserve confidentiality. Students had the option to turn the recording microphone off at any time to not have their comments recorded or used in the study regardless if they had previously consented. 
The seven, open-ended debriefing questions (see figure 1) were developed collectively by all the investigators. They were reviewed by a faculty member with expertise in qualitative research methodology and subsequently modified based on his feedback. The questions were posted on the screen during the debriefing session and the students were given freedom to comment on any question, in any order, and provide additional reflections about the experience as desired.

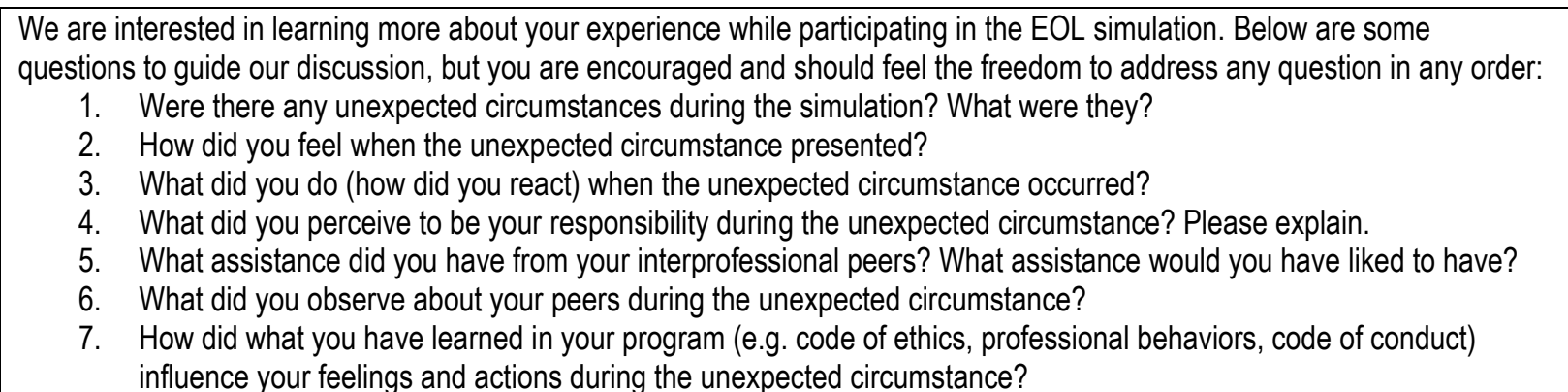

Figure 1. Debriefing Questions

\section{Data Analysis}

Qualitative data and analysis is particularly appropriate in situations where little is known about a complex subject, especially those involving processes. ${ }^{39}$ The focus of this study was to create a thematic structure that emerged from participant qualitative data. The researchers did not plan, nor claim to have developed theory. This is because the number of participants involved was preestablished and no claim of complete data saturation could be made. Having said that, some clear relationships emerged, which are described both visually by the thematic diagram and narratively in the results section.

The raw qualitative data were the transcribed words of the participants. The entire narrative of all participants was examined for meaning in a line-by-line manner to avoid missing any pertinent data. ${ }^{39}$ When the researchers had sufficient data to begin more layered comparisons, they continued line by line through every transcript, but added incident-to-incident coding for direct comparison of discreet situations that were common for many or all the students. ${ }^{39}$ Frequent and relevant codes were sorted using a process called focused coding, to allow the sifting of large portions of data, which later were grouped and more abstractly named to capture all the codes that fell into that category. ${ }^{40}$ These large categories became themes under which smaller concepts fell that helped describe the overall theme.

To aid in the sorting process, the researchers elected to use Corbin and Strauss' paradigmatic labeling to help categorize the large volume of data. ${ }^{39}$ The paradigmatic labels are conditions, actions/interactions/emotions, and consequences. ${ }^{39}$ More abstractly named themes were sorted into paradigmatic categories which helped "tell the story" of how the themes were used and thought to carry meaning.

The data analysis team, comprised of three researchers, met collectively over the course of many sessions to complete the coding and data analysis process. There was no independent coding carried out. All three of the researchers involved were from different disciplines (nursing, OT and SW). This provided theoretical sensitivity, allowing the analysis team to be sensitive to discipline specific contextual meaning in the participants' narratives, as described by Corbin and Strauss. ${ }^{39}$ Additionally, the data analysis team was led by a researcher who was present for all sessions and has extensive experience in qualitative research. This allowed for consistency and fidelity to the coding and thematic structure development. Finally, memos were completed in an on-going manner, to describe decisions made regarding code naming, sorting, and thematic development.

\section{Simulation Description}

Students participated in an interprofessional ethics simulation during which the patient dies while the emotionally charged family members become aggressive, confrontational, and upset towards each other. The roles of the parent and partner were played by standardized actors and the patient was a mannequin. Based on preparatory materials, the OT and PT student pair were under the impression that they were to conduct an initial evaluation with the patient. However, upon entering the room, the patient, who is in a same-sex relationship and has a do-not-resuscitate order, becomes unresponsive and the patient's parent and partner disagree on the care that should be provided. The nursing and SW students, who float between multiple "rooms" were available to help the therapy students as needed. The objectives of the simulation focused on both the ethical situation at hand and utilizing the role and skills of each interdisciplinary healthcare team member to appropriately address the needs of the patient and family 
members. Refer to Table 1 for a simulation experience description.

Table 1: Simulation Experience Description

\begin{tabular}{|c|c|c|}
\hline Timeframe & Research Study Component Description & Simulation Component Description \\
\hline 10 minutes & $\begin{array}{l}\text { Students were provided with a verbal and written } \\
\text { description of the research study, including details of } \\
\text { how data would be collected during the debriefing } \\
\text { sessions. } \\
\text { - Researcher available to answer any } \\
\text { - } \text { questions. } \\
\text { interested students were invited to sign an } \\
\text { informed consent. }\end{array}$ & $\begin{array}{l}\text { Students were provided with a brief written introduction } \\
\text { to the simulation scenario to review (simulation } \\
\text { objectives, hospital course information, presence of a } \\
\text { DNR order, description of family members at the } \\
\text { patient's bedside). } \\
\text { - OT and PT students were told that they } \\
\text { would be conducting an initial evaluation of a } \\
\text { patient. Therapy students had the } \\
\text { opportunity to develop a plan of action if } \\
\text { desired. } \\
\text { SW students were told they would be } \\
\text { available when requested to help deescalate } \\
\text { tension, advocate for the patient's wishes } \\
\text { and mediate as necessary. } \\
\text { Nursing students were told they would be } \\
\text { available when requested to help as needed. }\end{array}$ \\
\hline 10 minutes & & $\begin{array}{l}\text { Trained facilitators led prebriefing session for students } \\
\text { to remind them of the simulation objectives and } \\
\text { expectations: } \\
\text { - Recognize simulations are a safe, learning } \\
\text { environment to positively impact patient care } \\
\text { in the future } \\
\text { - Treat simulation as a real situation by } \\
\text { staying in role } \\
\text { - Keep details of simulation confidential to not } \\
\text { compromise future students' learning } \\
\text { experience }\end{array}$ \\
\hline 20 minutes & & $\begin{array}{l}\text { Students participated in interprofessional simulation } \\
\text { experience. } \\
\text { - OT and PT students entered the room to } \\
\text { begin evaluation session. } \\
\text { - Patient's parent and spouse began } \\
\text { emotionally charged interactions related to } \\
\text { patient's care. During the exchange, the } \\
\text { patient's heart rate began to drop resulting in } \\
\text { eventual death. } \\
\text { - The patient's family members continue in } \\
\text { emotional exchanges requiring intervention } \\
\text { by all/any of the healthcare students. } \\
\text { Possible interventions included explanation } \\
\text { of DNR order, de-escalation/comfort of } \\
\text { emotions, therapeutic presence/silence, and } \\
\text { offering additional resources. } \\
\text { - Debriefing facilitators present during } \\
\text { simulation. } \\
\text { Potential "unexpected circumstances" experienced by } \\
\text { students: same-sex relationship between patient and } \\
\text { spouse, patient dying during the simulation, }\end{array}$ \\
\hline
\end{tabular}




\begin{tabular}{|l|l|l|}
\hline 30 minutes & $\begin{array}{l}\text { At the beginning of each debriefing session, the } \\
\text { facilitators reminded the students of the research } \\
\text { study details. }\end{array}$ & $\begin{array}{l}\text { emotionally charged interactions between patient's } \\
\text { parent and spouse. }\end{array}$ \\
$\begin{array}{l}\text { Students were given the option to "opt out } \\
\text { During the debriefing, 7 questions were presented via } \\
\text { a PowerPoint slide to prompt student discussion. } \\
\text { of the study on the spot" (regardless if they } \\
\text { had signed the informed consent prior to } \\
\text { the simulation). }\end{array}$ & $\begin{array}{l}\text { Students that did not want their comments } \\
\text { to be included in the data collection were } \\
\text { instructed to turn off the recording device } \\
\text { prior to speaking. } \\
\text { Students were asked not to include any } \\
\text { identifying information (e.g. name, } \\
\text { discipline) in their comments. }\end{array}$ & \\
\hline
\end{tabular}

\section{RESULTS}

\section{Participant Demographics}

A total of 109 students participated in the simulations, with representation from each discipline, nursing $(n=14)$, OT $(n=36)$, PT $(n=45)$ and SW ( $n=14)$. Eighty-nine students signed the informed consent agreeing to participate. Due to the structure of the study, students had the opportunity to opt out on the spot during the debriefing whether they had previously signed the consent or not. In addition, students were not required to comment during the debriefing. Therefore, the exact number of participants in the study cannot be determined. Since the students were instructed not to identify themselves, their discipline or any other participant, the mix of disciplines of the participants also cannot be determined.

\section{Qualitative Results}

This study produced rich qualitative data. In addition to a narrative explanation, a thematic diagram depicting the major themes based on student responses and some relationships between themes where possible was developed (see Figure 2). The information in the blue boxes of the thematic diagram represents the pre-established concepts that the researchers were seeking to evaluate in the participants during the imposed scenario. Therefore, they do not represent actual data, which can be found in the white boxes. Consistent with Corbin and Strauss, the paradigmatic labels (conditions, actions/interactions/emotions, consequences), in the blue boxes, are the headings under which actual data were placed. ${ }^{39}$ The students' expectations, preparedness, and experience related in their roles and circumstances from previous simulations (conditions) led to interactions with the dynamics of this scenario (actions/interactions/emotions), which in turn resulted to both initial and secondary consequences. Therefore, the results are described in that order to facilitate explanation. However, the investigators recognize and acknowledge that there was a constant reflexive interplay among these three portions of the paradigmatic structure. 


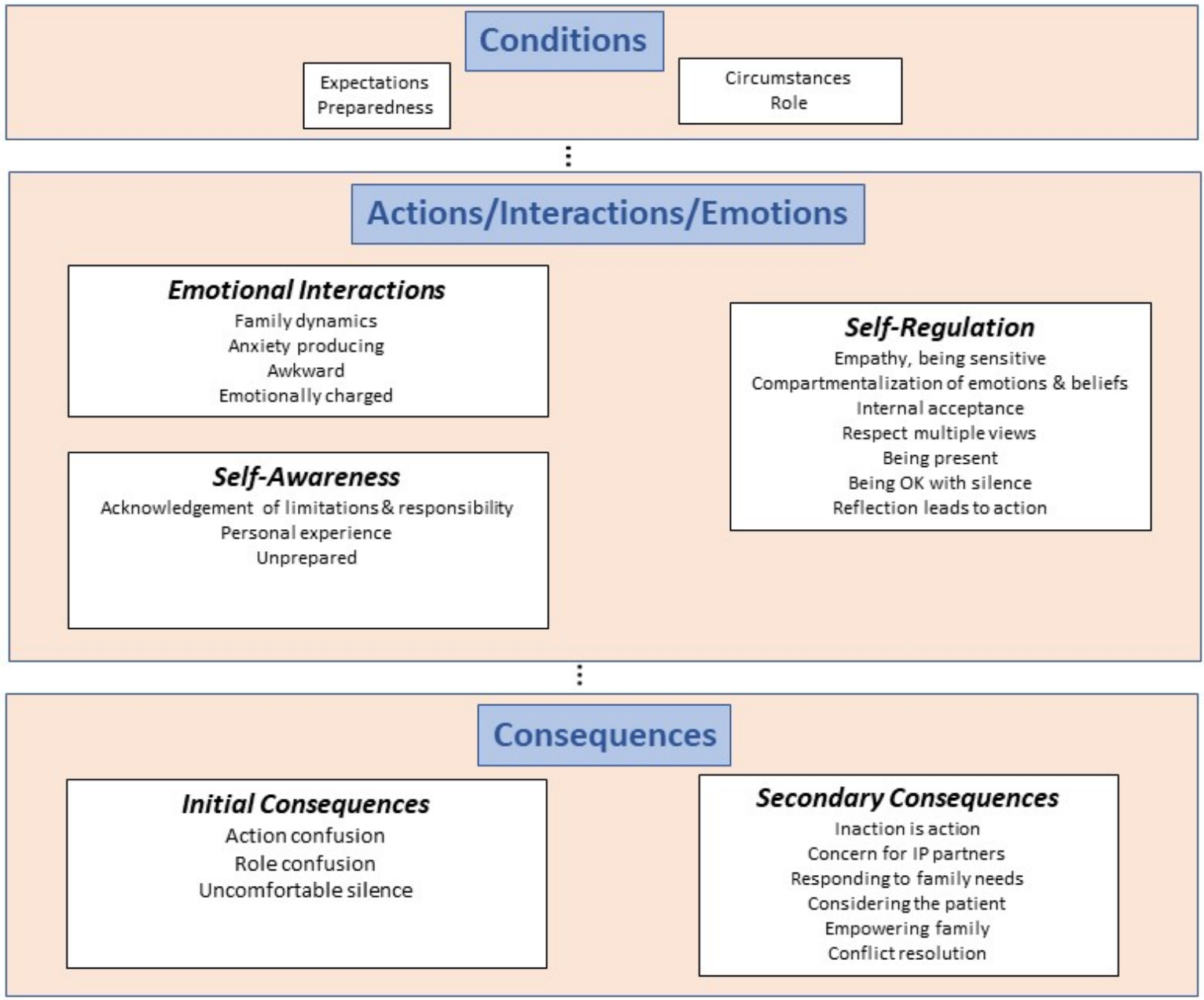

Figure 2. Self-Awareness, Self-Regulation, Simulation Scenario

\section{Theme 1: Expectations and Circumstances}

Participants suggested that the highly ethically based and emotionally charged scenario forced them to consider their roles and their preparation in new ways. Participants understood that the pre-determined scenario to which they were exposed, to some degree, drove their actions. During the debriefing sessions, there was much reflective discussion on preparation and what was or was not initially expected regarding the circumstances encountered. Based on previous simulation experiences, the students knew they were going to be exposed to a complex interprofessional clinical situation. However, as the scenario unfolded, it took them in a direction that they had not anticipated, and the students had to determine how to manage the situation in the moment. Some participants expressed concern about the degree to which their educational program was preparing them. Considering the complexity of the situation, the students had widely varying views about their level of preparedness ranging from not feeling prepared at all to philosophically believing that all providers must be prepared to handle these types of situations. One participant said, "you should be prepared for anything." Regarding their degree of preparation and the perceptions of the circumstances they faced, the investigators felt these fell into the category of conditions in the paradigmatic structure. ${ }^{39}$

\section{Theme 2: Emotional Interactions}

Data suggest that the participants found the situation to be highly charged; one in which they had to handle not only the health care needs of a patient, but difficult family dynamics. One participant felt particularly pressured by this challenge and suggested that the family members around the patient in the given scenario "ganged up on us." Participants described the challenging circumstances as anxiety-producing, awkward, and emotionally charged. One participant summed up his/her feelings by suggesting that he/she had no response for a family member of an obviously dying patient. The student said, speaking of a member 
of the patient's family, "she just kept repeating, like, you're letting my son die, you're letting him die, you're not doing anything, and that was just..... felt like I was at a loss for words." In the debriefing session, this caused student-participants to consider the degree to which they were prepared for this type of scenario, with one participant suggesting that "there's no way to prepare for any of that", and yet another coming to the realization that regardless of the circumstances, preparation is critical because, "you're going to be looked at as a professional walking into that room." The latter comment suggested that the participant understood that, though the situation may not lend itself to a discipline's expertise, it does not remove responsibility among all health professions from caring for patients and families in difficult situations. The anxiety and awkward feelings represented actions/interactions/emotions according to Corbin \& Strauss' paradigmatic structure when considering process analysis. ${ }^{39}$

\section{Theme 3: Self-Awareness}

Throughout the data, students repeatedly acknowledged being aware of their own responses and limitations during the situation, whether externally demonstrated or only internally perceived. For some students, they were aware that their presence was enough. One participant stated, "It's nice to remember to just be a body in the room." Others expressed feelings of fear and trepidation, which were overwhelming. One participant said, "I was just barely treading water." Another important theme related to selfawareness was accepting responsibility for the situation, regardless of professional roles. The words of one participant sum this up well; "So it was just kind of eye-opening I think for me in the moment, to be like no, I can do this. Like, this is ok, and it's ok for me not to focus on the physical needs of the patient, but the emotional needs of the patient and their family around them. And I do think that is part of our responsibility." Some participants also admitted that their own self-awareness was influenced by their own personal experiences with loved ones in similar situations, making them more acutely aware of the needs of the patient and especially the family. Of course, the anxiety-producing nature of the actions and interactions mentioned earlier (refer to Emotional Interactions) also revealed ways that participants were self-aware. Of feeling intimidated by one particularly over-bearing parent in the scenario, one participant said, "I could feel my heart beating a lot faster." Self-awareness fell primarily into the actions/interactions/emotions (albeit internal in many cases) paradigmatic category. ${ }^{39}$

\section{Theme 4: Self-Regulation}

The data revealed many examples of the participants engaging in self-regulation after having become aware of their own personal feelings and attitudes towards the unexpected circumstances. They applied self-regulatory behaviors including being truly and intentionally present with the patient and family, being sensitive, empathetic and being respectful of multiple views despite their own feelings, concerns, and beliefs. Given the scenario, this was particularly pertinent. Participants felt compelled to compartmentalize both personal beliefs and emotions to self-regulate. Regarding personal beliefs, one participant said; "I had to bracket my biases, and even thought that what they were arguing about wasn't important...it was clearly important enough to them." Compartmentalizing emotions was a challenge for some. One participant said, "You can't show that emotion and like, start crying or anything, but it was just sad." Another expressed a deep need for self-regulation, saying; "So it was kind of hard to like, stay in the room and not like, run away and be scared." An important and recurrent theme in self-regulation was knowing that silence was ok. One student said, "This is when silence needs to happen."

They acknowledged that reflection was necessary and led to further actions/interactions on the part of the participants. Participants stated that self-regulating allowed them to consider and respond to the needs of the patient and family more effectively. Because the scenario was complex, some said that it was important to remain focused. One participant said, "We just have to honor what the patient wanted...that's who we're ultimately serving." After self-regulating, the participants were able to make decisions and take action to improve the situation such as empowering the family, resolving conflict, and showing concern for and advising their interprofessional partners. Another important theme was internal acceptance that no one solution would completely resolve such a complex set of dilemmas. One participant said, "At the end of the day there might not be a solution that's going to satisfy everyone...being ok with the fact that you're not going to be able to fix it." Self-regulation was deemed to be primarily an action/interaction related to the paradigmatic structure..$^{39}$

Finally, while some students used self-awareness and self-regulation to help them navigate through the challenging situation and interactions during the simulation. For those that were not able to use those skills in the moment, they benefitted from observing others and from the reflective exchanges during the simulation and debriefing session.

\section{Theme 5: Circumstantial Consequences}

Participating in the scenario and experiencing the awkwardness and anxiety of the emotionally charged situation led to certain initial consequences, a component of Corbin and Strauss' paradigmatic structure. ${ }^{39}$ Participants very frequently expressed confusion about what to do because of the complexity of the situation. The confusion seemed to be centered around two basic questions: 1) What is my role here? and 2) What action should or should not be taken? 
The data were rich in providing information about the students' perceptions related to their discipline-specific roles as the situation was carefully designed to help them think through an interprofessional approach to care. Participants expressed concerns about their own role responsibilities, and the roles of others. These concerns primarily centered on what they should or should not be doing based on their profession. One participant summed it up by saying, "I didn't really know how to find my place in the situation." Students were also concerned about their roles and functions being dynamic, rather than static as they noted their responsibilities shifting during the scenario. They were also concerned about the lack of resources available and the family members' perceptions of the role of each professional in the scenario.

Students also experienced action confusion. Action confusion, which was abstractly named, included questions related to what actions should be taken, not taken, and when and how to best meet family needs, what are appropriate physical touch and emotional boundaries, what legal and policy concerns needed to be followed and how to make difficult decisions. As the students contemplated these concerns and questions internally, there were delays in the interactions with the patient and family members. One participant described these moments as an "awkward gap" and another questioned "When do we step in and talk?" Many of the students mentioned feeling uncomfortable with the awkward silences that occurred throughout the scenario.

In the analysis, some participants appeared to provide statements that seemed to be more summative of important factors to be remembered for future practice rather than what they experienced and did during the simulation. These "takeaways" were secondary consequences. Whether it was being silent or remaining present, the students learned throughout the simulation that inaction is action. Also, a very frequent code encountered were those in which participants acknowledged one another and the benefit and help they received from those of other disciplines. Students realized that they needed one another. Evidence of this is a comment suggesting that; "I thought it was a really good partnership." One participant commented, "calling for help isn't a weakness at all." Some thought that the team approach was the most effective way to address the patient and family's needs and as mentioned under the theme of self-regulation, after the students were able to self-regulate, they could empower the family and provide more conflict resolution.

\section{DISCUSSION}

The simulation scenario was carefully crafted to include unexpected/unforeseen components in terms of patient needs, exposing students to the environment they will enter as healthcare providers (e.g., end of life setting, patient expiring during scenario, do not resuscitate orders, presence of telemetry monitors, lines, and tubes) and patient/family communication and interactions (e.g. estranged family members, differing views on same-sex relationships, emotionally charged family dynamics with heated exchanges, extreme sadness). ${ }^{18,27,32-33,37}$ Through experiential learning, the students had to use their non-technical skills (e.g., leadership, conflict resolution, interprofessional and patient communication, decision-making) to maintain overall patient safety and effectively navigate through the difficult family dynamics. ${ }^{1-10}$ The standardized actors brought a dimension of reality to the simulation that can be difficult otherwise to reach as the students learned to communicate with the family members while navigating through a difficult situation within the simulated environment. 18, 27, 32-33, 37 While the students recognized that they could not ever be fully prepared for this type of scenario, they acknowledged the need to be more prepared and recognized the importance of having these types of opportunities embedded into their educational curriculum for exposure and practice within a safe and supportive environment, which is consistent with the literature. ${ }^{3-4,6}$

The simulation also provided the students with a strong interprofessional education experience, focused on the IPEC core competencies while exercising self-awareness and self-regulation both during and after the scenario unfolded. ${ }^{3-4,11,38}$ Because the simulation did not require the students to use their more clearly defined technical skills, the students wrestled with identifying their own role and responsibilities within the simulation leading to some action confusion. Ultimately the students recognized that despite what they initially thought they were supposed to do, they had a responsibility to address the family's needs when the patient's condition deteriorated, which was eye opening..$^{10}$ This led them to first recognize and regulate their own feelings and emotions and then rely on other interdisciplinary team members' strengths and assistance for successful outcomes. ${ }^{4,15,16}$ The students acknowledged an awareness of their own responses to the unexpected circumstances - feelings of fear, trepidation, intimidation and being overwhelmed, realizing their own limitations, and need for help from other team members. Instead of casting these feelings in a negative light, they acknowledged their need for one another. ${ }^{12-15,38}$ While the silence and "just being present" at times felt awkward for the students, they were able to recognize this was the most appropriate action to take. Also, through their intentional interdisciplinary communication and teamwork, the students drew from each other's strengths and skill sets to best handle the situation, provided each other advice on what to do next and showed concern for each other. Because the scenario included components that challenged some students' comfort level, values, and ethics, they had to act despite what they felt or thought. The students used self-regulation to compartmentalize their own feelings and opinions to remain focused and carefully 
meet the needs of the family which was most important. ${ }^{15-18}$ The students engaged in self-regulatory behaviors to be truly and intentionally present with the patient and family through sensitivity, empathy, and respect for multiple views.

\section{STUDY LIMITATIONS AND FUTURE RESEARCH DIRECTIONS Limitations}

While the students acknowledged the benefit of participating in the interprofessional simulation on their own self-awareness and regulation when experiencing an unexpected circumstance, there are some study limitations to be noted. The recruitment methods and incentives offered to students differed between disciplines (e.g. course requirement, volunteer, extra credit) potentially impacting results and willingness to participate in the study. Also, all the students were required to participate in the debriefing process as part of the complete learning experience; however, not all were required to speak aloud or participate in the study. Therefore, the data recorded and analyzed might not fully reflect all the students' thoughts and experience and it is possible that comments made by students who did not participate in the study may have influenced participating students. Additionally, while the disciplines that were represented within the simulation (nursing, OT, PT, and SW) is known, the disciplines of the students that participated in the study is not known since the students did not identify their disciplines within the recordings. The variation in technical knowledge, stage in program, and specific program curriculums across the disciplines could have impacted study results. Another limitation of the study was the range of interactions demonstrated by the standardized actors. They were provided guidelines on how to act during the scenario; however, they were also given some flexibility as to what emotions they chose to do and level of intensity to display (e.g. anger, sadness, aggressiveness, withdrawn, crying). Also, because the nursing and SW students were floating between "rooms," they saw three different scenarios which might not have been realistic in an end of life situation and could have possibly impacted how they progressively acted in each scenario. Finally, the debriefing facilitators were provided with a script on how to conduct the session; however, depending on student comments and which questions the students chose to respond to, there was some variation in the focus group discussion during each session.

\section{Future Research}

There are future research opportunities available to build on this study's findings. To ensure more consistency across groups and for reproduction in other programs, more rigorous scripts could be developed for the standardized actors and debriefing facilitators which would require piloting. Also, another study could investigate the impact of the simulation experience on self-awareness and self-regulation skills specific to each discipline or additional disciplines (e.g. medicine, pharmacy, clergy) could be included to see if the interprofessional interactions change. Finally, this simulation experience could be replicated at another university or with additional cohorts of students to confirm and expand upon this study's conclusions and recommendations.

\section{CONCLUSION}

The interprofessional clinical simulation provided students with the opportunity to navigate through a challenging and unexpected circumstance both personally and alongside their interdisciplinary team members. The students had to rely on their non-technical skills by specifically becoming self-aware of their own responsibility, feelings, and biases and then self-regulating those internal emotions in order to externally balance managing the emotionally charged interactions of the family members while respecting the patient's wishes. The participants gained a greater appreciation for their interprofessional colleagues as they relied on them in the moment as the scenario unfolded and through the debriefing process reflection. Not all students felt prepared to handle the unexpected situation and did not always know how to respond; however, they appreciated the needed simulation experience to further prepare them for future practice. Additional opportunities for students to practice using their non-technical skills throughout their educational curriculum is warranted and could impact their ability to maintain personal well-being, effectively interact with patients and their families, and function as part of the interdisciplinary team in a demanding and unpredictable healthcare environment. 


\section{References}

1. Brown T, Crabtree JL, Mu K, Wells J. The Issue Is-The next paradigm shift in occupational therapy education: The move to the entry-level clinical doctorate. Am J Occup Ther. 2015;69(Suppl. 2):6912360020. doi: 10.5014/ajot.2015.016527. [PMID 26539686]

2. Huston C. Preparing nurse leaders for 2020. J Nurs Manag. 2008;16: 905-911. doi: 10.1111/j.1365-2834.2008.00942.x. [PMID 19094101]

3. Por J, Barriball L, Fitzpatrick J, Roberts J. Emotional intelligence: Its relationship to stress, coping, well-being and professional performance in nursing students. Nurse Educ Today. 2011;31(8):855-860. doi: 10.1016/j.nedt.2010.12.023 [PMID 21292360]

4. Flin R, Patey R. Improving patient safety through training in non-technical skills. BMJ. 2009;339:b3595. doi: 10.1136/bmj.b3595. [PMID 19776108]

5. Case-Smith J, Page SJ, Darragh A, Rybski M, Cleary D. The issue is - The professional occupational therapy doctoral degree: Why do it? Am J Occup Ther, 2014;68: e55-e60. doi: 10.5014/ajot.2014.008805. [PMID 24581414]

6. Carragher J, Gormley K. Leadership and emotional intelligence in nursing and midwifery education and practice: A discussion paper. J Adv Nurs. 2017;73(1): 85-96. doi: 10.1111/jan.13141. [PMID 27607451]

7. Gordon M, Baker P, Catchpole K, Darbyshire D, Schocken D. Devising a consensus definition and framework for nontechnical skills in healthcare to support educational design: A modified Delphi study. Med Teach. 2015;37(6):572-577. doi: 10.3109/0142159X.2014.959910. [PMID 25244065]

8. Gordon M. Non-technical skills training to enhance patient safety. Clin Teach. 2013;10(3):170-175. doi: 10.1111/j.1743498X.2012.00640.x. [PMID 23656679]

9. Brudvig TJ, Dirkes A, Dutta P, Rane K. Critical thinking skills in health care professional students: A systematic review. J Phys Ther Educ. 2013;27(3):12-25.

10. Frenk J, Chen L, Bhutta ZA, et al. Health professionals for a new century: Transforming education to strengthen health systems in an interdependent world. Lancet. 2010;376(9756):1923-1958. doi: 10.1016/S0140-6736(10)61854-5. [PMID 21112623]

11. Birks $Y$, Mckendree J, Watt I. Emotional intelligence and perceived stress in healthcare students: A Multi-institutional, multiprofessional survey. BMC Med Educ. 2009;9:61. doi: 10.1186/1472-6920-9-61. [PMID 19761603]

12. Van Rooy DL, Viswesvaran $C$. Emotional intelligence: $A$ meta-analytic investigation of predictive validity and nomological net. J Vocat Behav. 2004;65:71-95. doi: 10.1016/S0001-8791(03)00076-9.

13. Psychology Resource Centre. BarOn Emotional Quotient Inventory - Short (BarOn EQ-i:S). Psychology Resources Centre website. https://psycentre.apps01.yorku.ca/wp/baron-emotional-quotient-inventory-short-baron-eq-is/. Published October 9 , 2018. Accessed August 8, 2019.

14. Salovey P, Mayer JD. Emotional intelligence. Imagin Cogn Pers. 1990;9:185-211. doi: 0.2190/DUGG-P24E-52WK-6CDG. 18

15. Goleman D. What makes a leader? Harv Bus Rev. 1998;76(6):93-102. [PMID 10187249]

16. Finlay-Jones AL, Rees CS, Kane RT. Self-compassion, emotional regulation and stress among Australian psychologists: Testing an emotion regulation model of self-compassion using structural equation modeling. PLoS. 2015;10(7):e0133481. doi: 10.1371/journal.pone.0133481. [PMID 26207900]

17. Scherbaum S, Frisch S, Holfert AM, O'Hora D, Dschemuchadse M. No evidence for common processes of cognitive control and self-control. Acta Psychol (Amst). 2018;182: 194-199. doi: 10.1016/j.actpsy.2017.11.018. [PMID 29202280]

18. Pedersen I, Solevåg AL, Solberg MT. Simulation-based training promotes higher levels of cognitive control in acute and unforeseen situations. Clin Simul Nurs. 2019;34:6-15. doi.org/10.1016/j.ecns.2019.05.003.

19. Tyler LS. Emotional intelligence: Not just for leaders. Am J Health Syst Pharm. 2015;72(21):1849. doi: 10.2146/ajhp150750. [PMID 26490817]

20. Salovey P, Grewal D. The science of emotional intelligence. Curr Dir Psychol Sci. 2005;14:281-285. doi: 10.1111/j.09637214.2005.00381.x.

21. Martins $A$, Ramalho N, Morin $E$. A comprehensive meta-analysis of the relationship between emotional intelligence and health. J Pers Individ Dif. 2010;49:554-564. doi: 10.1016/j.paid.2010.05.029

22. Schutte NS, Malouff JM, Thorsteinsson EB, Bhullar N, Rooke SE. A meta-analytic investigation of the relationship between emotional intelligence and health. Pers Individ Dif. 2007;42(6):921-933. doi: 10.1016/j.paid.2006.09.003. 
23. Humpel N, Caputi P. Exploring the relationship between work stress, years of experience and emotional competency using a sample of Australian mental health nurses. J Psychiatr Ment Health Nurs. 2001;8:399-403. doi: 10.1046/j.13652850.2001.00409.x. [PMID 11882159]

24. Weng HC, Hung CM, Liu YT, et al. Associations between emotional intelligence and doctor burnout, job satisfaction and patient satisfaction. Med Educ. 2011;45(8):835-842. doi: 10.1111/j.1365-2923.2011.03985.x. [PMID 21752080]

25. Peddle M. Virtual simulation developing non-technical skills in student nurses and midwives. Aust Nurs Midwifery J. 2015;23(1):41. doi: 10.2146/ajhp150750. [PMID 26226822]

26. Shoemaker MJ, Riemersma L, Perkins R. Use of high fidelity human simulation to teach physical therapist decision-making skills for the intensive care setting. Cardiopulm Phys Ther J. 2009;20(1):13-18. doi: 10.1097/01823246-200920010-00003. [PMID 20467529]

27. Pritchard SA, Blackstock FC, Nestel D, Keating JL. Simulated patients in physical therapy education: Systematic review and meta-analysis. Phys Ther. 2016;96(9):1342-53. doi: 10.2522/ptj.20150500. [PMID 26939603]

28. Cahill SM. Perspectives on the use of standardized parents to teach collaboration to graduate occupational therapy students. Am J Occup Ther. 2015;69(Suppl. 2):6912185040. doi: 10.5014/ajot.2015.017103. [PMID 26539677]

29. Cheng A, Palaganas J, Eppich W, Rudolph J, Robinson T, Grant V. Co-debriefing for simulation-based education: A primer for facilitators. Simul Healthc. 2015;10(2):69-75. doi: 10.1097/SIH.0000000000000077.

30. Cook, D. A., Hamstra, S. J., Brydges, R., et al. Comparative effectiveness of instructional design features in simulationbased education: Systematic review and meta-analysis. Med Teach. 2013;35(1):867-898. doi: 10.3109/0142159X.2012.714886. [PMID 22938677]

31. Bennett S, Rodger S, Fitzgerald C, Gibson L. Simulation in occupational therapy curricula: A literature review. Aust Occup Ther J. 2017;64(4):314-327. doi: 10.1111/1440-1630.12372. [PMID 28378428]

32. Fesler D. Interprofessional communications using simulation and standardized patients. Okla Nurse. 2018;63(3):9-10.

33. Ha EH. Experience of nursing students with standardized patients in simulation-based learning: Q-methodology study. Nurse Educ Today. 2018;66:123-129. doi: 10.1016/j.nedt.2018.04.023. [PMID 29702441]

34. Giles AK, Carson NE, Breland HL, Coker-Bolt P, Bowman PJ. Conference proceedings - Use of simulated patients and reflective video analysis to assess occupational therapy students' Preparedness for fieldwork. Am J Occup Ther. 2014;68(Suppl. 2):57-S66. doi:10.5014/ajot.2014.685s03.

35. INACSL Standards Committee. (2016). INACSL standards of best practice: Simulation ${ }^{S M}$ facilitation. Clin Simul Nurs. 2016;12(S):S16-S20. doi:10.1016/j.ecns.2016.09.007.

36. Mariani B, Cantrell MA, Meakim C. Nurse educators' perceptions about structured debriefing in clinical simulation. Nurs Educ Perspect. 2014;35(5):330- 331. doi: 10.5480/13-1190.1. [PMID 25291930]

37. Hoelzer BC, Moeschler SM, Seamans, DP. Using simulation and standardized patients to teach vital skills in pain medicine fellows. Pain Med. 2015;16(4):680-691. doi: 10.1111/pme.12694. [PMID 25677571]

38. Interprofessional Education Collaborative [IPEC]. Core competencies for interprofessional collaborative practice: 2016 update. Washington, DC: Interprofessional Education Collaborative; 2016.

39. Corbin C, Strauss A. Basics of qualitative research: Techniques and procedures for developing grounded theory. Thousand Oaks, CA: Sage Publications; 2015.

40. Charmaz K. Conducting grounded theory: A practical guide through qualitative analysis. Thousand Oaks, CA: Sage Publications; 2014 